\title{
Unraveling the Effects of Tropical Cyclones on Economic Sectors Worldwide: Direct and Indirect Impacts
}

\author{
Sven Kunze ${ }^{1}$ (D) \\ Accepted: 21 January 2021 / Published online: 10 March 2021 \\ (C) The Author(s) 2021
}

\begin{abstract}
This paper examines the current, lagged, and indirect effects of tropical cyclones on annual sectoral growth worldwide. The main explanatory variable is a new damage measure for local tropical cyclone intensity based on meteorological data weighted for individual sectoral exposure, which is included in a panel analysis for a maximum of 205 countries over the 1970-2015 period. I find a significantly negative influence of tropical cyclones on two sector aggregates including agriculture, as well as trade and tourism. In subsequent years, tropical cyclones negatively affect the majority of all sectors. However, the Input-Output analysis shows that production processes are sticky and indirect economic effects are limited.
\end{abstract}

Keywords Natural disasters · Climate impact analysis · Sectoral GDP growth · Tropical cyclones $\cdot$ Input-output analysis

JEL Classification Q54·Q56·O44 · O11

\section{Introduction}

Tropical cyclones can have devastating economic consequences. Globally they are among the most destructive natural hazards. From 1980 to 2018 tropical cyclones were responsible for nearly half of all natural disaster losses worldwide, with damage amounting to an aggregate of USD 2111 billion (Munich Re 2018). Driven by climate change, at least in some ocean basins (Elsner et al. 2008; Mendelsohn et al. 2012), and the higher exposure of people in large urban agglomerations near oceans (World Bank 2010), the overall damage and the number of people affected by tropical cyclones have been increasing since the 1970s (Guha-Sapir and CRED 2020). Thus, tropical cyclones are and will continue to be a serious threat to the life and assets of a large number of people worldwide.

In order to design effective mitigation and adaptation disaster policies to this threat, it is important to understand the economic impact of natural disasters. Economic sectors most

Sven Kunze

sven.kunze@awi.uni-heidelberg.de

1 Alfred-Weber-Institute for Economics, Heidelberg University, Bergheimerstrasse 58, Heidelberg 69115, Germany 
vulnerable to direct capital destruction of tropical cyclones must be identified. However, time-delayed effects must also be taken into account since some damage, such as supplychain interruptions or demand-sided impacts, will only be visible after a certain time lag (Kousky 2014; Botzen et al. 2019). Perhaps the most challenging task is to identify critical sectors that may be responsible for widespread spillover effects leading to substantial modifications in other sectors' production input schemes. This study aims to better understand the sectoral impacts of tropical cyclones by looking at the direct and indirect effects in a large data set covering 205 countries from 1970 to 2015 . Additionally, a new damage measure is developed that considers the varying levels of exposure of different sectors.

From a theoretical perspective, a natural disaster can have both positive and negative effects. Direct negative impacts can result from the destruction of productive capital, infrastructure, or buildings, and thereby can generate a negative income shock for the whole economy (Kousky 2014). Positive effects include, for instance, as a consequence of the destruction of capital, that the marginal productivity of capital increases, making it more attractive to invest in capital in the affected area (Klomp and Valckx 2014). Furthermore, a shortage in the labor force can lead to a wage increase, which can serve as an incentive for workers from other regions to migrate to the affected region, also leading to a positive effect (Hallegatte and Przyluski 2010). Given the different theoretical possibilities, it is not surprising that the empirically identified effects are rather ambiguous. They can best be summarized by three possible hypotheses: recovery to trend, build-back-better, and no recovery (Chhibber and Laajaj 2008).

The recovery to trend hypothesis characterizes a pattern where after a negative effect in the short run, the economy recovers to the previous growth path after some time. For example, Miranda et al. (2020) provide evidence that after hurricane strikes in Central America, a short-term negative growth period (12 months) is compensated by a positive recovery in the second year. Possible mechanisms for this situation are, for example, additional capital flows - such as remittances from relatives living abroad (Yang 2008)—international aid (de Mel et al. 2012), insurance payments (Nguyen and Noy 2019), or government spending (Ouattara and Strobl 2013), which help the economy reach its pre-disaster income level. Other studies identify negative effects that are only significant in the short run but are insignificant in the long run (Strobl 2012; Bertinelli and Strobl 2013; Elliott et al. 2015).

The build-back-better hypothesis describes a situation where natural disasters first trigger a downturn of the economy, which is then followed by a positive stimulus, leading to a higher growth path than in the pre-disaster period. This hypothesis is supported by empirical findings for a positive GDP growth effect for Latin American countries (Albala-Bertrand 1993), for high-income countries (Cuaresma et al. 2008), and for a cross-section of 153 countries (Toya \& Skidmore 2007). Additionally, Cole et al. (2019) find a build-backbetter effect for plants that survived the 1995 Kobe earthquake and Mohan et al. (2019) demonstrate that there exist a short-term productivity efficiency increase after damaging hurricanes in the Caribbean.

In contrast to this, the no recovery hypothesis states that natural disasters can lead to a permanent decrease of the income level without the prospect of reaching the pre-disaster growth path again. ${ }^{1}$ This could result from a situation where recovery measures are not effectively implemented or where various negative income effects accumulate over time (Hsiang and Jina 2014; Onuma et al. 2020). Additionally, it has been shown, that low- and middle-income countries seem to be more vulnerable to the negative impacts of natural

\footnotetext{
1 This does not mean that there have to exist a permanent negative growth effect for every period after the disaster. It is possible that the economy exhibits positive growth rates after a first negative growth shock. However, these growth rates are simply not high enough to reach the pre-disaster growth path.
} 
disasters than high-income countries (Felbermayr and Gröschl 2014; Berlemann and Wenzel 2018).

This paper contributes to two strands of the literature. First, I add to the research area on the macroeconomic effects of disasters. Older empirical studies suffer to a large extent from endogeneity problems in their econometric analysis because their damage data are based on reports and insurance data, such as the Emergency Events Database (EM-DAT). Such data are positively correlated with GDP (Felbermayr and Gröschl 2014) and prone to measurement errors (Kousky 2014). More recent studies have started to use physical data, such as observed wind speeds, to generate a more objective damage function for the impacts of tropical cyclones (e.g., Hsiang 2010; Strobl 2011; Felbermayr and Gröschl 2014; Bakkensen et al. 2018; Elliott et al. 2019). To address the varying economic exposure of affected areas, studies have used population (Strobl 2012), nightlight intensity (Heinen et al. 2018) or exposed area (Hsiang and Jina 2014) to weight the respective physical intensities of tropical cyclones. However, an area weight has the disadvantage of including largely unpopulated areas, such as deserts, which are economically meaningless. In contrast, for the agricultural sector, it would be misleading to take a nighttime light or a population weight, since these areas have a rather low population density. Therefore, I propose a new damage measure that explicitly considers these different exposures. For the agricultural sector, I use the fraction of exposed agricultural land, while for the remaining sectors, I use the gridded population.

Furthermore, only a minority of studies explicitly investigate the disasters' influences on sectoral economic development. For example, Loayza et al. (2012) investigate the effect of natural disasters on three sectors (agriculture, manufacturing, service) in a global sample for the period 1961-2005. Based on damage estimates from EM-DAT, the authors find a negative effect for the agricultural and a positive effect for the industrial sector. Based on physical intensity data, Hsiang (2010) analyzes the effect of hurricanes on seven sectoral aggregates in a regional study for 26 Caribbean countries. He finds a negative effect for the ISIC sectors agriculture, hunting, forestry, and fishing (A\&B), mining, and utilities (C\&E), wholesale, retail trade, restaurants, and hotels $(\mathrm{G}-\mathrm{H})$, but a positive effect for the construction sector $(\mathrm{F})$. Other studies analyze the disasters' impact on single sectors, such as the agricultural (Blanc and Strobl 2016; Mohan 2017) or the manufacturing sector (Bulte et al. 2018).

In total, I extend this research area in three ways: First, I introduce a new objective damage measure that allows for sector specific exposure of tropical cyclones. It is based on a physical wind model and thereby overcomes criticism of report-based damage data. Second, I use this new damage data to analyze all (exposed) countries (84) to tropical cyclones worldwide, which allows me to obtain more generalizable results. ${ }^{2}$ Third, I conduct a thorough assessment of the long-term sectoral influences of tropical cyclones, as there is evidence, that long-term effects on total GDP exist (Felbermayr and Gröschl 2014; Hsiang and Jina 2014; Onuma et al. 2020). For sectoral GDP effects, however, no such evidence exists so far.

Second and most importantly, I contribute to the literature on Input-Output analysis of natural disasters. While there exists a lot of theoretical work on the importance of cross-sectional linkages in consequence of a shock (see e.g., Dupor 1999; Horvath 2000; Acemoglu et al. 2012), recent empirical studies focus on the shock propagation in production networks within the United States of America (Barrot \& Sauvagnat 2016) or after single natural disasters, such as the 2011 earthquake in Japan (Boehm et al. 2019; Cole et al. 2019). These empirical studies all share that they use firm-level data to

\footnotetext{
2 This is an improvement in comparison to Hsiang (2010) who only focuses on 26 Caribbean countries, which are highly exposed but only account for 11\% of global GDP in 2015 (United Nations Statistical Division 2015c).
} 
draw conclusions on upstream and downstream production disruptions. However, little is known about the empirical Input-Output effects across broader sectors after a natural disaster shock. In a single country study on floods in Germany, Sieg et al. (2019) show that indirect impacts are nearly as high as direct impacts. For tropical cyclones, no empirical cross-country study on indirect effects exists so far. With this paper, I close this research gap by using an Input-Output panel data set to analyze potential sectoral interactions after the occurrence of a tropical cyclone. This allows me to analyze whether any key sectors exist that, if damaged, result in direct damage of other sectors.

The main causal identification stems from the exogenous nature of tropical cyclones, whose intensity and position are difficult to predict even $24 \mathrm{~h}$ before they strike (NHC 2016). Based on a fine-gridded wind field model, I generate a new sector-specific damage measure weighted by either agricultural land use or population data. This exogenous measure allows me to identify an immediate negative growth effect of tropical cyclones for two out of seven sectoral aggregates including agriculture, hunting, forestry, and fishing and wholesale, retail trade, restaurants, and hotels. The largest negative impacts can be attributed to the annual growth in the agriculture, hunting, forestry, and fishing sector aggregate, where a standard deviation increase in tropical cyclone damage is associated with a decrease of 262 percentage points of the annual sectoral growth rate. This corresponds to a mean annual global loss of USD 16.7 billion (measured in constant 2005 USD) for the sample average. In the years following a tropical cyclone, the majority of sectors experience negative growth effects. Within the agriculture, hunting, forestry, and fishing sectors, the negative effects become less pronounced with a zero effect being present after four years, while the wholesale, retail trade, restaurants, and hotels sectoral aggregate experiences a persistent negative growth even after 20 years.

Based on the Input-Output analysis, there are only a small number of significant sectoral shifts. This suggests that the production chains of the economy are only slightly disrupted by tropical storms, and indirect impacts are thus negligible. Nevertheless, we can learn from this analysis the important role of those manufacturing sectors that are not directly affected. They are responsible for a demand shock in the mining and quarrying sectoral aggregate, leading to delayed negative growth effects being persistent over 10 years. At the same time, other sectors demand more from the manufacturing sectors, resulting in a zero aggregate negative effect for them. Additionally, within the agriculture, hunting, forestry, and fishing sectors, only the fishing sector experiences indirect negative effects. Moreover, for the vast majority of sectors, the indirect effects do not last longer than one year.

The remainder of this paper is structured as follows: Sect. 2 contains a description of the data source, introduces the construction of the tropical cyclone damage measure, and presents descriptive statistics. In Sect. 3, the empirical approach is described. Section 4 presents the main results as well as robustness checks. Section 5 concludes with a discussion of the results and highlights policy implications.

\section{Data}

\subsection{Tropical Cyclone Data}

Tropical cyclones are large, cyclonically rotating wind systems that form over tropical or sub-tropical oceans and are mostly concentrated on months in summer or early autumn in both hemispheres (Korty 2013). Their destructiveness has three sources: damaging winds, 
storm surges, and heavy rainfalls. The damaging winds are responsible for serious destruction of buildings and vegetation. In coastal areas, storm surges can lead to flooding, the destruction of infrastructures and buildings, the erosion of shorelines, and the salinization of the vegetation (Terry 2007; Le Cozannet et al. 2013). Torrential rainfall can cause serious in-land flooding, thereby augmenting the risk coming from storm surges (Terry 2007).

Since the commonly used report-based EM-DAT data set (Lazzaroni and van Bergeijk 2014) has been criticized for measurement errors (Kousky 2014), endogeneity, and reverse causality problems (Felbermayr and Gröschl 2014), I use meteorological data on wind speeds to generate a proxy for the destructive power of tropical cyclones. ${ }^{3}$ This approach is in line with previous empirical studies (e.g., Hsiang 2010; Strobl 2011, 2012), but I advance this literature by generating a sector-specific damage function. I take advantage of the International Best Track Archive for Climate Stewardship (IBTrACS) provided by the National Oceanic and Atmospheric Administration (Knapp et al. 2010). It is a unification of all best track data on tropical cyclones collected by weather agencies worldwide. Best track data are a postseason reanalysis from different available data sources, including satellites, ships, aviation, and surface measurements, that are used to describe the position and intensity of tropical cyclones (Kruk et al. 2010). ${ }^{4}$

To calculate a new aggregate and meaningful measure of tropical cyclone damage separated by economic sectors on a country-year level, I make use of the CLIMADA model developed by Aznar-Siguan and Bresch (2019) at a resolution of $0.1^{\circ} .5$ The model employs the well-established Holland (1980) analytical wind field model to calculate spatially varying wind speed intensities around each raw data observation track. ${ }^{6}$ The model is restricted to raw data wind speed intensities above $54 \mathrm{~km} / \mathrm{h}$ and it interpolates the 6 -h raw data observations from the IBTrACS data to hourly observations. ${ }^{7}$

Consequently, for each grid point $g$, a wind speed $S$ is calculated depending on the maximum sustained wind speed $(M)$, the forward speed $(T)$, the distance $(D)$ from the storm center, and the radius of the maximum wind $(R)^{8}$ :

$$
S_{g}= \begin{cases}\max \left(0,\left((M-a b s(T)) * \frac{R}{D} \frac{3}{2}^{2} * e^{1-\frac{R}{D} \frac{3}{2}}\right)+T\right), & \text { if } D<10 * R \text { from center to outer core } \\ 0, & \text { if } D>10 * R \text { out of radius. }\end{cases}
$$

\footnotetext{
3 For example, Loayza et al. (2012) use data from EM-DAT as main input for their explanatory variables. They are, however, aware of data problems, such as incomplete reports, fluctuating quality of the reports, and correlation with GDP. Therefore, they take 5-year averages of the number of affected people normalized by the total population as main explanatory variable. In comparison, in my analysis, I take meteorological data as input which is exogenous to the political and economic situation, contains all existing tropical cyclones, and has no quality fluctuations.

4 Further details on the data on tropical cyclones can be found in Appendix A.1.

$50.1^{\circ}$ corresponds to approximately $10 \mathrm{~km}$ at the equator.

6 See the CLIMADA manual for furher details on the methods used https://github.com/davidnbresch/clima da/blob/master/docs/climada_manual.pdf.

7 For the latitude and longitude the model takes a spline interpolation, whereas for intensity and time observations it uses a linear interpolation.

8 The radius of maximum wind $(R$, in $\mathrm{km})$ is related to the latitude $(L)$ of the respective raw data tropical cyclone position in the following way:

$$
R= \begin{cases}30, & \text { if } L \leqq 24^{\circ} \\ 30+2.5 * a b s(L)-24, & \text { if } L>24^{\circ} \\ 75, & \text { if } L>42^{\circ}\end{cases}
$$
}




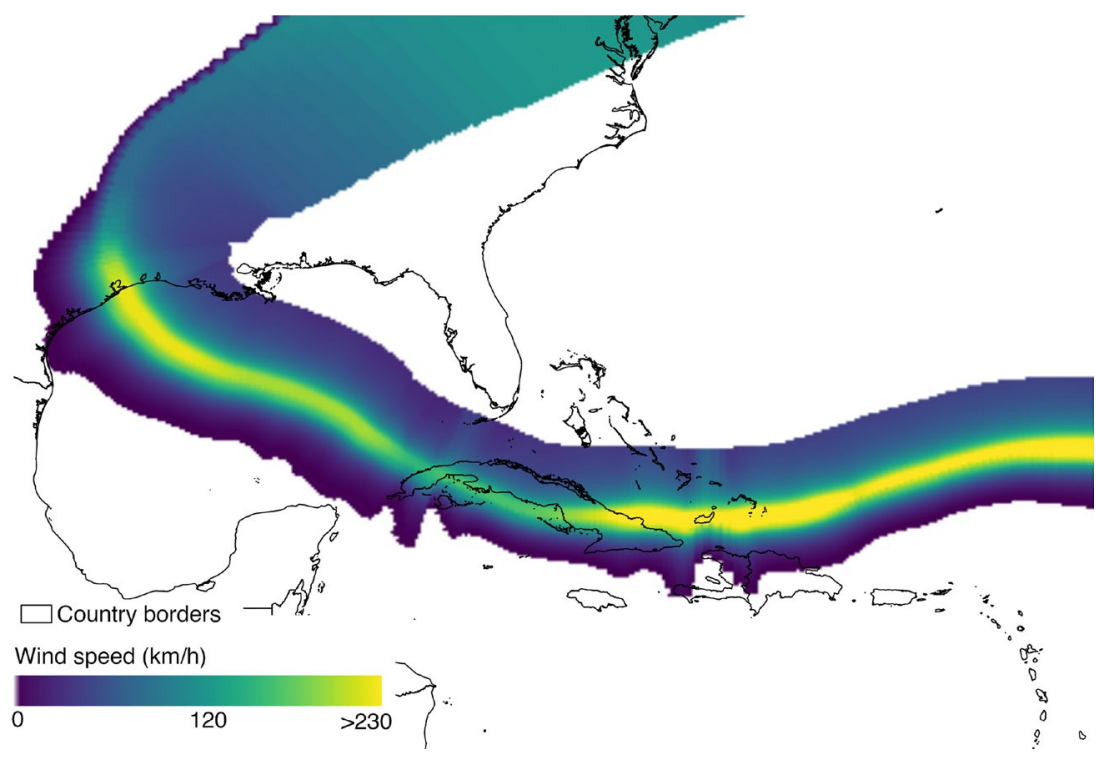

Fig. 1 Wind field model for Hurricane Ike, 2008

As a result, I generate hourly wind fields for each of the 7814 tropical cyclones in my sample period (1970-2015). ${ }^{9}$ Figure 1 illustrates the resulting modeled wind fields for Hurricane Ike in 2008 on its way to the U.S. coast. The individual colors represent different wind speed intensities. The wind speed drops with distance to the center of the hurricane and as soon as it makes landfall.

One major effort of this paper is to generate a new meaningful sectoral damage variable on a country-year level. In total, I use two different aggregation methods. First, I account for the economic exposure by weighting the maximum occurred wind speed per grid cell and year by the number of exposed people living in that grid cell relative to the total population of the country. This is a well-established method (Strobl 2012; Heinen et al. 2018; Elliott et al. 2019). However, since agricultural areas are seldom highly populated, using a population-weighted damage function for the agricultural sectors would be biased. Therefore, I propose a new spatial exposure weight for the agricultural sector, namely agricultural land, which consists of the sum of land used for grazing and crops in $\mathrm{km}^{2}$ per grid cell. All weights are available in the HYDE 3.2 data set (Klein Goldewijk et al. 2017) at a spatial resolution of around $10 \times 10 \mathrm{~km} .{ }^{10}$ To avoid potential endogeneity concerns, I lag the respective weights by one period.

Figure 2 demonstrates why it is important to differentiate between exposed agriculture and population. Panel (a) displays the percentage of agricultural land, whereas (b) shows the distribution of population in Australia in 2008. A damage function that takes into account only the exposed population would underestimate the damage caused to the

\footnotetext{
9 Since the tropical cyclone data are available at global coverage since 1950, I will extend my database later for further specifications.

10 Before 2000, only decadal data are available. Hence, I interpolate the data to generate yearly observations.
} 

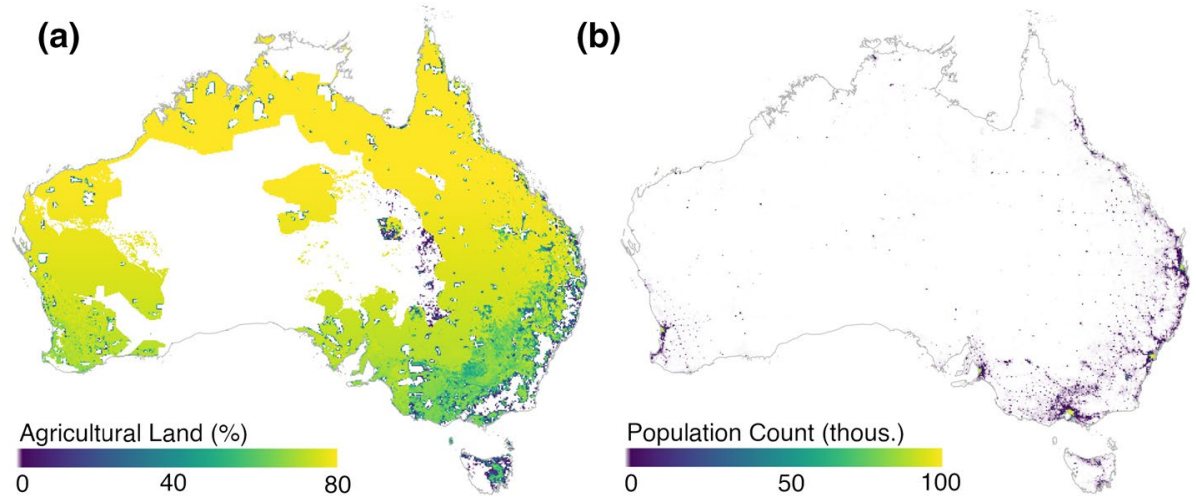

Fig. 2 Agricultural land and population count in Australia, 2008

agricultural sector, given the large unpopulated but agriculturally used areas in the north and west of Australia.

It has been shown that the damage of tropical cyclones increases non-linearly with wind speed and occurs only above a certain threshold. I follow Emanuel (2011) by including the cube of wind speed above a cut-off wind speed of $92 \mathrm{~km} / \mathrm{h}$. Taking all considerations together, I calculate the following tropical cyclone damage for each country $i$ and year $t$ :

$$
\text { Damage }_{i, t}=\frac{\sum_{g \in i} w_{g, t-1}}{W_{i, t-1}} * \sum_{g \in i} S(\max )_{g, t}^{3} \mathbb{1}_{S(\max )>92},
$$

where $w_{g, t-1}$ are the exposure weights, agricultural land, or population, in grid $g$ in period $t-1$. The sum of these exposure weights $w_{g, t-1}$ is divided by the total sum of the weights $W_{i, t-1}$ in country $i$ in period $t-1$. This index is then multiplied by the cubed maximum wind speed $S(\max )_{g, t}^{3}$ in grid $g$ and year $t$ as calculated by Eq. 1 but only for values above $92 \mathrm{~km} / \mathrm{h}$.

There are two important points to note about this tropical cyclone damage variable. First, I only use the damage fraction due to maximum wind speed of tropical cyclones. Even though, I thereby omit potential rainfall and storm surge damage, it is a common simplification in the literature (Hsiang 2010; Strobl 2011; Strobl 2012; Elliott et al. 2019). However, to control for possible rainfall damage, I conduct a robustness test which includes a variable for precipitation (see Appendix Table 24 and and Figs. 26-32). For storm surge damage this is not possible, since there exists no global data set so far.

Second, only the maximum wind speed per grid cell and year is used for the calculation of the tropical cyclone damage. This means that if a grid cell of a country was exposed to two storms in one year, only the physically more intense storm is considered. In the sample used, $70 \%$ of all grid-points are hit once by a tropical cyclone per year, whereas $20 \%$ are hit twice and $10 \%$ more than twice. To allow for the possibility of multiple tropical cyclones per year and country, I conduct two robustness tests. In the first test, I introduce a variable which counts the yearly frequency of tropical cyclones above $92 \mathrm{~km} / \mathrm{h}$ per country (see Appendix Table 40 and Figs. 26-32). In the second test, I take the mean wind speed cubed $\left(S(\text { mean })_{g, t}^{3}\right)$ above $92 \mathrm{~km} / \mathrm{h}$ per grid and year to calculate the damage $_{i, t}$ (see Appendix Table 41 and Figs. 26-32). 


\subsection{Sectoral GDP Data}

The sectoral GDP data originates from the United Nations Statistical Division (UNSD) (United Nations Statistical Division 2015b). Sectoral GDP is defined as gross value added per sector aggregate and is collected for different economic activities following the International Standard Industrial Classification (ISIC) revision number 3.1. Gross value added is defined by the UNSD as "the value of output less the value of intermediate consumption" (United Nations Statistical Division 2015a). The variables are measured in constant 2005 USD. The different economic activities are classified as follows with the respective ISIC codes given in parentheses: agriculture, hunting, forestry, and fishing (A\&B); mining, and utilities $(C \& E)$; manufacturing $(D)$; construction $(F)$; wholesale, retail trade, restaurants, and hotels $(G-H)$; transport, storage, and communication (I); other activities $(J-P)$, which include, inter alia, the financial and government sector. Appendix A.3 provides a more detailed description of the composition of the individual ISIC categories. The data are collected every year for as many countries and regions as possible. ${ }^{11}$ The sample used in my analysis covers the 1970-2015 period and includes a maximum of 205 countries. $^{12}$

\subsection{Input-Output Data}

To analyze potential sectoral shifts within the economy after a tropical cyclone, I take advantage of the Input-Output data of EORA26 (Lenzen et al. 2012, 2013). It provides data on 26 homogeneous sectors for 189 countries from 1990 until 2015 and is the only Input-Output panel data set with (nearly) global coverage available. However, one disadvantage of the EORA26 data set is that parts of the data are estimated and not measured. On the other hand, EORA26 works continuously on quality check reports and compares its result to other Input-Output databases such as GTAP or WIOD. ${ }^{13}$

To be consistent with the remaining analysis, I aggregate the given 26 sectors to the previously used seven sectoral aggregates. ${ }^{14}$ For my analysis, I calculate the Input-Output coefficients by dividing the specific input of each sector by the total input of each sector given in the transaction matrix of the data:

$$
I O_{t}^{j, k}=\frac{\text { Input }_{t}^{j, k}}{\text { TotalInput }_{t}^{j}}
$$

The resulting Input-Output coefficients $I O^{j, k}$ range between 0 and 1 in year $t$. They indicate how much input from sector $k$ is needed to produce one unit of output of sector $j$. Consequently, the Input-Output coefficients give an idea of the structural interactions of sectors

\footnotetext{
11 If the official data of the countries or regions are not available, the UNSD consults additional data sources. The procedure is hierarchical and reaches from other official governmental publications over publications from other international organizations to the usage of data from commercial providers (United Nations Statistical Division 2015b).

12 The sample is larger than the maximum size of recognized sovereign states as it also includes quasiautonomous countries such as the Marshall Islands, if data are provided for them by the UNSD. Furthermore, one can argue that only countries exposed to tropical cyclones are relevant for this analysis; therefore, Table 36 provides a regression of the main result for exposed countries only.

13 I decide not to use the WIOD database because its country sample is not very exposed to tropical cyclones. Additionally, the GTAP database is not freely available and only covers a few years.

${ }^{14} \mathrm{I}$ also explore the effects on the 26 individual sectors later in this paper.
} 
within an economy and hence help to disentangle the indirect effects of tropical cyclone damage. ${ }^{15}$

\subsection{Further Control Data}

As tropical cyclones are highly correlated with higher temperature and precipitation (Auffhammer et al. 2013), I control for the mean temperature and precipitation of a country in further specifications. For both variables, I use the year-by-year variation calculated from the Climatic Research Unit (CRU) version 4.01, which is available at a resolution of approximately $50 \mathrm{~km}$ since 1901 (University of East Anglia Climatic Research Unit et al. 2017). Together with further control variables, Table 2 in Appendix A.4 lists the exact definition of all variables used.

\subsection{Descriptive Statistics}

Figure 3 shows the country-year observations of the tropical cyclone damage variable for (a) exposed agricultural land and (b) exposed population. Country-year observations above two standard deviations are labeled with the respective ISO3 code. While the distribution reveals that on average, geographically smaller countries, such as Hong Kong, Dominica or Jamaica, have a higher damage, there exists a difference between both damage measures, even for the highly exposed countries. Moreover, extreme damaging tropical cyclones are relatively rare. A one standard deviation strong event has a probability of $8.9 \%$ among events above zero for agricultural damage and $8 \%$ for population damage. ${ }^{16}$

To demonstrate the average intersectoral connections within my sample, Fig. 4 displays the average Input-Output coefficients for all countries for all available years (1990-2015). The different colors represent different average coefficients, ranging from 0 (light purple) to 0.24 (dark purple). On average, the sector aggregates agriculture, hunting, forestry, and fishing $(A \& B)$ and mining and utilities $(C \& E)$ are only slightly dependent on other sectors, while there is a stronger dependence for the remaining sectoral aggregates. The crosssectoral dependence is most pronounced for the manufacturing $(D)$ and other activities $(J-P)$ sectoral aggregates. This is not surprising since the manufacturing $(D)$ sector needs a lot of input materials from other sectors (Sieg et al. 2019), and the sector other activities $(J-P)$ comprises, among others, the financial sector. Tables 3 and 4 in Appendix A.5 show the main descriptive statistics for all variables used in this study.

\footnotetext{
15 I decide to only examine changes in the Input-Output coefficients and not at indirect costs because it almost needs no assumptions. Input-Output models that analyze indirect costs, such as the Inoperability Input-Ouptut model (Haimes and Jiang 2001) or the Ghosh model (Ghosh 1958), require many assumptions that tend to be problematic (Oosterhaven 2017).

16 The underlying calculations for these numbers are as follows: agricultural damage: $91 / 1027=0.0886$, population damage: $82 / 1035=0.0801$.
} 


\section{Empirical Approach}

\subsection{Direct Effects}

In order to examine tropical cyclones as exogenous weather shocks, I pursue a panel data approach with year and country fixed effects in a simple growth equation framework (Strobl 2012; Dell et al. 2014). The analysis is conducted on a country-year level. To identify the causal effects of tropical cyclone intensity on sectoral per capita growth, I use the following set of regression equations, which constitutes my main specifications:

$$
\text { Growth }_{i, t-1->t}^{j}=\alpha^{j}+\beta^{j} * \text { Damage }_{i, t}+\gamma^{j} * \mathbf{Z}_{i, t-1}+\delta_{t}^{j}+\theta_{i}^{j}+\mu_{i}^{j} * t+\epsilon_{i, t}^{j},
$$

where the dependent variable Growt $h_{i, t-1->t}^{j}$ is the annual value added per capita growth rate of sector $j$ in country $i$. The main specification is estimated for each of the $j(=1, \ldots, 7)$ sector aggregates separately. Damage $e_{i, t}$ is the derived damage function for country $i$ at year $t$ from Eq. 2. Consequently, $\beta^{j}$ is the coefficient of main interest in this specification. By calculating the annual sectoral GDP per capita growth rate, I lose the first year of observation of the panel. The sample period hence reduces to 1971-2015. In further specifications, I include additional control variables $\mathbf{Z}_{i, t-1}$ to account for potential socioeconomic or climatic influences. Moreover, I include time fixed effects $\delta_{t}$ to account for time trends and other events common to all countries in the sample. The country fixed effects $\theta_{i}$ control for unobservable time-invariant country-specific effects, such as culture, institutional background, and geographic location. Additionally, I allow for country-specific linear trends $\mu_{i} * t$. This assumption is relaxed in further specifications by allowing more flexible country-specific trends (e.g., squared). The error term $\epsilon_{i, t}$ is clustered at the country level.

The growth literature predicts that some potential positive or negative impacts of natural disasters emerge only after a few years. It is therefore important to examine their effects over time (Felbermayr and Gröschl 2014; Hsiang and Jina 2014). To analyze the effect of tropical cyclones in the longer run, I introduced lags of the tropical cyclone damage variable to the main specification 4. Since the tropical cyclone data has global coverage since 1950, I am able to introduce lags of up to 20 years without losing observations of my dependent variable, which ranges from 1971 to 2015. This allows me to identify which of the competing hypotheses-build-back-better, recovery to trend, or no recovery-is appropriate for which sector. In detail, this model can be described by the following set of regression equations:

$$
\begin{aligned}
\text { Growth }_{i, t-1->t}^{j}= & \alpha^{j}+\sum_{L=0}^{20}\left(\beta_{t-L}^{j} * \text { Damage }_{i, t-L}\right)+\gamma^{j} * \mathbf{Z}_{i, t-1} \\
& +\delta_{t}^{j}+\theta_{i}^{j}+\mu_{i}^{j} * t+\epsilon_{i, t}^{j},
\end{aligned}
$$

where all variables are defined as in Eq. 4. I show point coefficient estimates as well as accumulated effects and error statistics calculated via a linear combination of the lagged $\beta_{t-L}$ coefficients. $^{17}$

\footnotetext{
17 This approach follows Hsiang and Jina (2014) which analyze the accumulated long-term GDP growth effects of tropical cyclones worldwide. I expand their approach by not looking at overall GDP but at disaggregated GDP responses for seven sectoral aggregates. Furthermore, I use a more specific damage function than Hsiang \& Jina (2014) which takes account of different sectoral exposure.
} 
(a) Wind Damage for exposed agriculture (in st. dev.)

(b) Wind Damage for exposed population (in st. dev.)
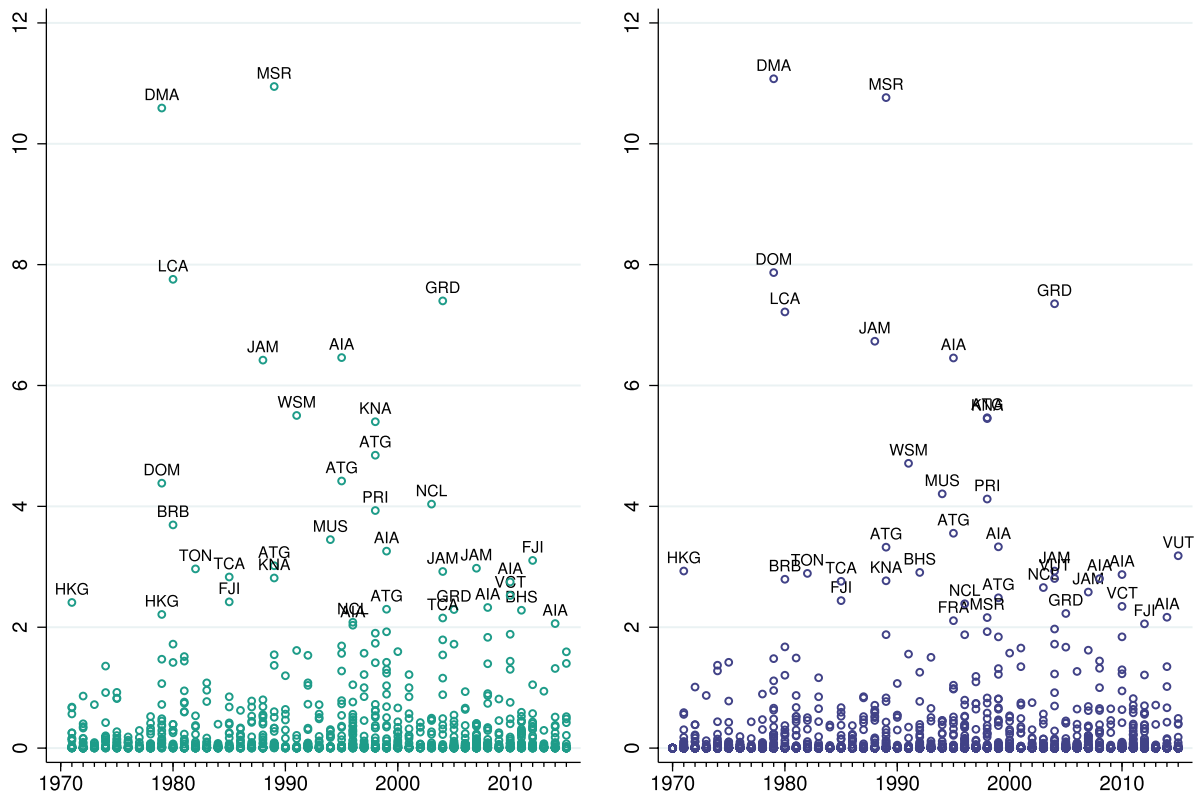

Fig. 3 Distribution of tropical cyclone damage, 1970-2015. Notes This figure demonstrates the distribution of the tropical cyclone damage variable (in standard deviations) for exposed agricultural areas (a) and exposed population (b) from 1970 to 2015

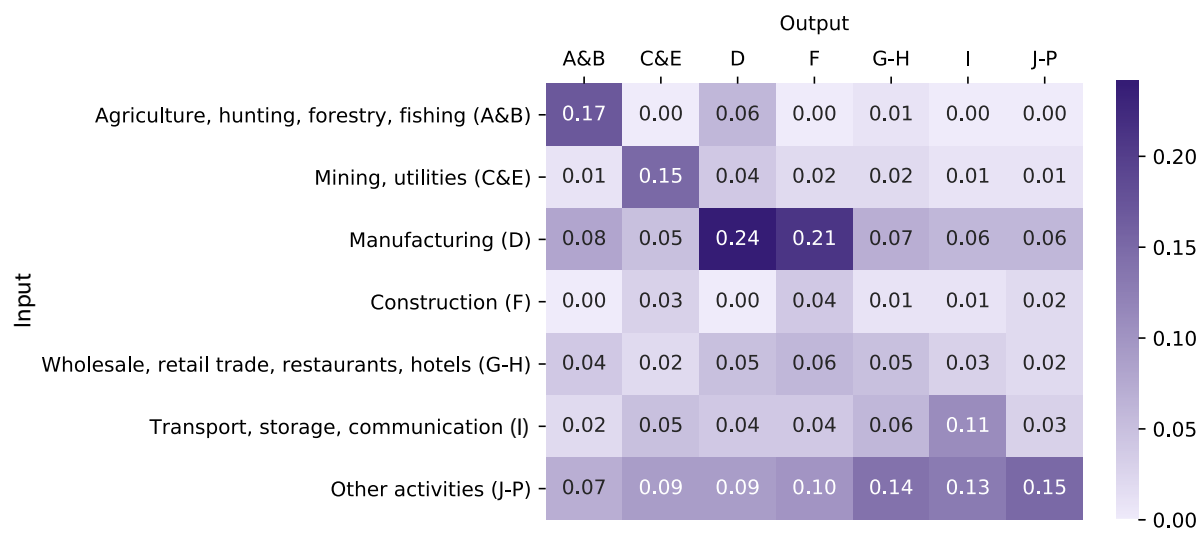

Fig. 4 Heatmap of Input-Output coefficient averages, 1990-2015. Notes Input-Output coefficients show how much input one sector needs to produce one unit of output. The coefficients range between zero and one

\subsection{Indirect Effects}

To analyze potential indirect effects which could emerge because of changes in the Input-Output composition of the individual sectors, I test the following set of equations for the different $\operatorname{Input}(j)-\operatorname{Output}(k)$ combinations: 


$$
\begin{aligned}
I_{i, t}^{j, k}= & \alpha^{j, k}+\beta^{j, k} * \text { Damage }_{i, t}+\lambda^{j, k} * I O_{i, t-1}^{j, k}+\gamma^{j, k} * \mathbf{Z}_{i, t-1} \\
& +\delta_{t}^{j, k}+\theta_{i}^{j, k}+\mu_{i}^{j, k} * t+\epsilon_{i, t}^{j, k},
\end{aligned}
$$

where $I O_{i, t}^{j, k}$ indicates the Input-Output coefficient of sectors $j$ and $k$ in year $t$ and country $i$. Depending on the level of aggregation, I run $49(7 * 7)$ or $676(26 * 26)$ different regressions. In contrast to Eq. 4, I introduce a lagged dependent variable, since I suspect a strong path dependence of the Input-Output coefficient, i.e., most sectors plan their inputs at least one period ahead. Additionally, the lagged dependent variable controls for a sluggish adjustment to shocks of the individual sector input composition. The remaining variables are defined as in Eq. 4. In general, this analysis reveals production scheme transformations that can result from both supply and demand changes of the sectors due to tropical cyclones.

\subsection{Identification Strategy}

The main causal identification stems from the occurrence of tropical cyclones, which are unpredictable in time and location (NHC 2016) and vary randomly within geographic regions (Dell et al. 2014). As demonstrated in Fig. 3, their intensity and frequency are spread considerably between years and countries. Additionally, tropical cyclone intensity is measured by remote sensing methods and other meteorological measurements. After controlling for country and time specific effects, my estimation approaches allow for a causal identification of the direct and indirect responses to tropical cyclones' damages with only little assumption needed (Dell et al. 2014). To underpin the causal identification, I conduct a falsification test, where I introduce leads instead of lags of the Damage variable, as well as a Fisher randomization test. Furthermore, one could also argue that the estimation results are biased by the fact that certain regions have a higher exposure to tropical cyclones than others. However, the country fixed effects partly control for this concern. Additionally, I cluster the standard errors at broader regional levels as a further robustness test.

As tropical cyclones are exogenous to sectoral economic growth, the greatest threat to causal identification could arise by omitting important climatic variables that are correlated with tropical cyclones (Auffhammer et al. 2013). Therefore, I include the mean level of temperature and precipitation as additional climate controls in a further specification. Both variables are associated with the occurrence of tropical cyclones since they only form when water temperatures exceed $26{ }^{\circ} \mathrm{C}$ and torrential rainfalls usually constitute part of them.

To be in line with the related growth literature, I estimate a further specification where I add a set of socioeconomic control variables (Islam 1995; Strobl 2012; Felbermayr and Gröschl 2014). It comprises the logged per capita value added of the respective sector $j$ to simulate a dynamic panel model, the population growth rate, a variable for openness (i.e., imports plus exports divided by GDP), and the growth rate of gross capital formation. ${ }^{18}$ Including these socioeconomic control variables introduce some threats to causal inference. First, as shown by Nickell (1981), there is a systematic bias of panel regressions with a lagged dependent variable and fixed effects. However, it has been demonstrated that this bias can be neglected if the panel is longer than 15 time periods (Dell et al. 2014). As my

\footnotetext{
18 The logged per capita value added is not included for the robustness tests of the indirect effects of model 6 , because it already compromises a lagged dependent variable.
} 
panel has a length of 25-45 years, depending on the chosen model, I assume this bias will not influence my analysis. ${ }^{19}$ Second, all control variables are measured in $t-1$ to reduce potential endogeneity problems stemming from the fact that control variables in $t$ can also be influenced by tropical cyclone intensities in $t$ (Dell et al. 2014). Admittedly, this will not fully solve potential endogeneity problems, and concerns about bad controls (Angrist \& Pischke 2009) and "over-controlling" (Dell et al. 2014) remain.

Finally, the standard errors $\epsilon_{i, t}$ could be biased by the autocorrelation of unobservable omitted variables (Hsiang 2016). To deal with this problem, I will re-estimate my regression models with Newey and West (1987) as well as spatial HAC standard errors (Hsiang 2010; Fetzer 2020), which allow for a temporal correlation of 10 years and a spatial correlation of 1000 kilometer radius. ${ }^{20}$

Generally speaking, the proposed models offer a simple but strong way for causal interpretation of the impact of tropical cyclones on sectoral growth. The weighted tropical cyclone damage variables are orthogonal to economic growth as well as the Input-Output coefficients, and the panel approach allows me to identify the causal effect.

\section{Results}

\subsection{Direct Effects}

Table 1 presents the results of the main specification for each of the seven annual sectoral GDP per capita growth rates. The coefficients show the increase of the respective damage variable by one standard deviation. Previous empirical studies on the relationship between economic development and tropical cyclone damage found a negative influence on GDP growth (e.g., Strobl 2011; Bertinelli and Strobl 2013; Gröger and Zylberberg 2016). My results indicate that this negative aggregate effect can be attributed to two sectoral aggregates, including agriculture, hunting, forestry, and fishing; manufacturing and wholesale, retail trade, restaurants, and hotels. Tropical cyclones have the largest negative effect on the agriculture, hunting, forestry, and fishing aggregate compared to other sectoral aggregates. The absolute size of this effect is approximately more than 2.5 times the size of the coefficient in the wholesale, retail trade, restaurants, and hotels sector aggregate. In general, a one standard deviation increase in tropical cyclone damage is associated with a decrease in the annual growth rate in the sector aggregate agriculture, hunting, forestry, and fishing of -2.62 percentage points. For the sample average $(0.88)$ of the regression of Column (1), this effect can be translated into a decrease of $-298 \%$, as displayed in Fig. 5. In terms of total losses, this decrease results in a mean yearly loss of USD - 16.7 billion (measured in constant 2005 USD) for the sample average (USD 5.63 billion). This large negative effect is not surprising. The agricultural sector relies heavily on environmental

\footnotetext{
${ }^{19}$ For the dynamic analysis, the panel length is 65 years, and for the Input-Output regression, it comprises 20 years.

${ }^{20}$ I tested my data extensively for outliers having a high influence on my results. In particular, I calculated the leverage and dfbeta of the damage coefficient. Observations were excluded if they were above the $(2 k+2) / n$ threshold for leverage and above the $2 / \operatorname{sqrt}(n)$ threshold for dfbeta. In total, I exclude five country-year observations from my analysis: Dominican Republic 1979, Grenada 2004, Montserrat 1989, Myanmar 1977, and Saint Lucia 1980. However, as an additional robustness test, I also show a regression where I include these outliers and the results remain unchanged.
} 


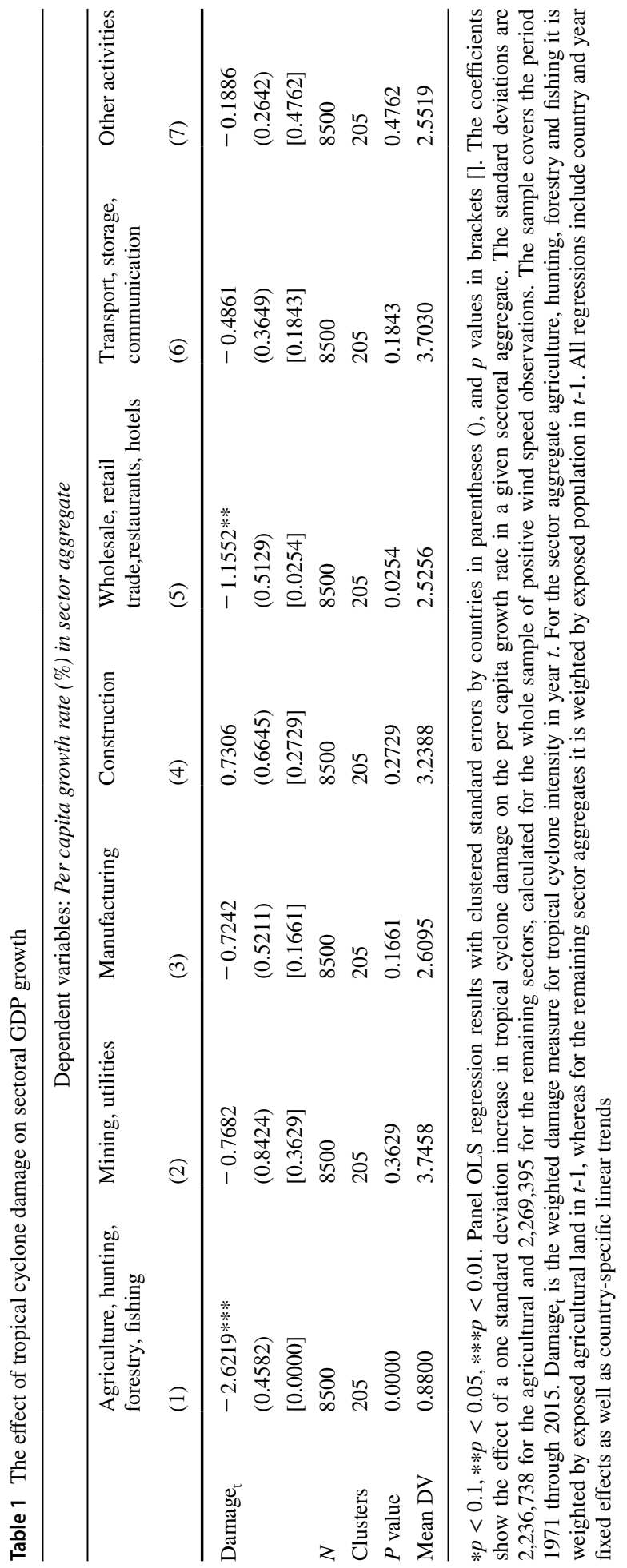




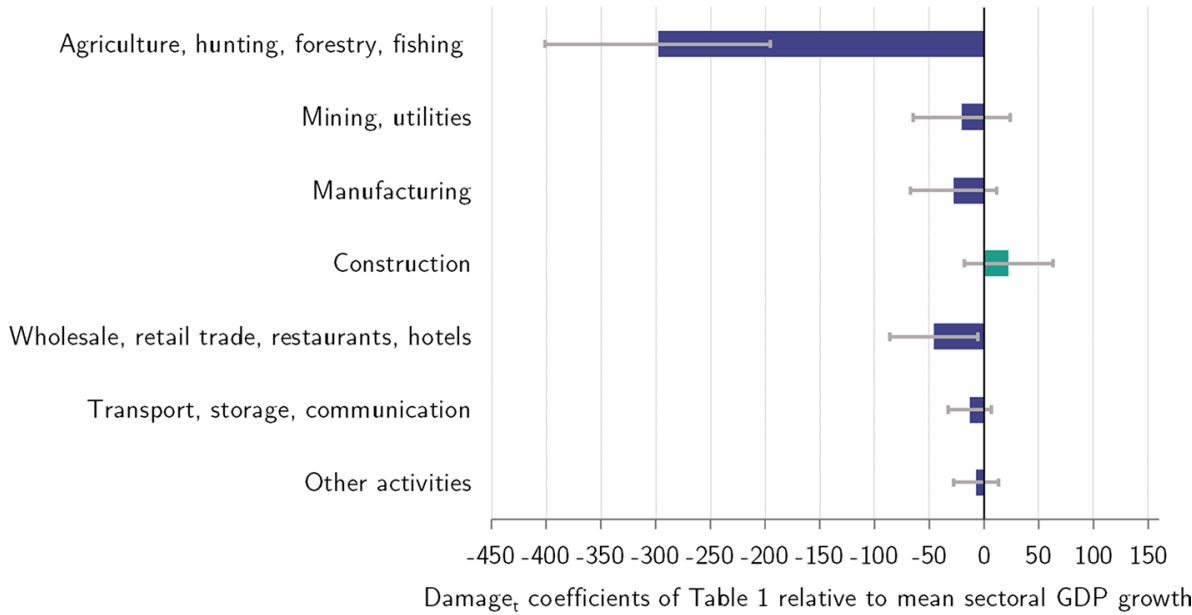

Fig. 5 Effects of tropical cyclone damage on sectoral GDP growth compared to sample average. Notes This figure shows the effect of a one standard deviation increase in tropical cyclone damage on the per capita sectoral GDP growth rate compared to the respective sample average. The damage estimates can be found in Table 1. The error bars depict the $95 \%$ confidence intervals

conditions as most of its production facilities lie outside of buildings and are hence more vulnerable to the destructiveness of tropical cyclones. In addition to damaging wind speed, salty sea spread and storm surge can cause salinization of the soil, leaving it useless for cultivation.

These results are line with previous empirical studies. Hsiang (2010) also finds the largest negative effects of tropical cyclones for the agricultural sector aggregate, while Loayza et al. (2012) demonstrate that only the agricultural sector is negatively affected. Mohan (2017) provides further evidence that in Caribbean countries agricultural crops are more severely affected by hurricanes compared to livestock.

For the sector aggregate wholesale, retail trade, restaurants, and hotels, a one standard deviation increase in tropical cyclone damage cause a decrease of -1.16 percentage points of the annual per capita growth rate. Put in relation to the sample average per capita growth rate $(2.53 \%)$, the effect translates to a decrease of $-46 \%$. Hsiang (2010) also finds a negative effect of hurricanes for this sectoral aggregate for the Caribbean countries, whereas Loayza et al. (2012) find no significant for the service sector. ${ }^{21}$ Likely reason for this downturn could be less (domestic and international) touristic income for the restaurant and hotel sectors (Hsiang 2010; Lenzen et al. 2019). In consequence to tropical cyclone damage, less tourists visit affected countries (Hsiang 2010), since they perceive these destinations as too risky to travel to (Forster et al. 2012).

It is not empirically clear how long past tropical cyclones influence present economic growth rates. While some studies provide evidence of only a short-term economic impact of tropical cyclones (Bertinelli and Strobl 2013; Elliott et al. 2019), Felbermayr and Gröschl (2014) show that storms from the previous five years can also have a negative growth effect. In addition, in a recent working paper, Hsiang and Jina (2014) even demonstrate a long-term negative impact of tropical cyclones of up to 20 years.

${ }^{21}$ Loayza et al. (2012) only differentiate between three sectors: agriculture, manufacturing, and service. 
Figure 6 illustrates the cumulative point estimates of the past influence of tropical cyclone damage on the different sectoral growth variables. ${ }^{22}$ The $x$-axis represents the lags of the damage variable, while the $y$-axis indicates the size of the cumulative coefficient $\beta$ (in standard deviations). The gray shaded area specifies the respective $95 \%$ confidence bands, and the red line depicts the connected estimates. Appendix A.5 presents further statistics: Figs. 13-15 show the cumulative results for different lag lengths $(5,10,15)$, and Tables 13-15 exhibit the underlying estimations. The individual point estimates are shown in Figs. 9-12, while Tables 5-11 show the regression results.

Figure 6 demonstrates that three out of seven sectoral aggregates suffer from delayed negative impacts of tropical cyclones. The agriculture, hunting, forestry, and fishing sector aggregate first depicts negative growth rates but then quickly recovers after four years. Despite having the largest negative shock, destroyed capital is relatively quickly replaced. The situation is completely different in the wholesale, retail trade, restaurants, and hotels sector aggregate, where a negative influence can be observed over almost the entire 20-year period. This finding undermines the evidence presented in the main specification: Even several years after the occurrence of a tropical cyclone, tourists avoid restaurants and hotels in devastated areas. This behavior most likely speaks for an enduring risk adjustment of tourists.

Surprisingly, the sector aggregate mining and utilities turns negative three years after the tropical cyclone has hit the country. As Sect. 4.2 demonstrates, this effect may be driven by less demand from the manufacturing sectors. Upon examining the underlying estimates in Tables 12-13 in Appendix A.5, it is evident that the transport, storage, communication sectoral aggregate also turns negative, at least at the $90 \%$ confidence interval. ${ }^{23}$

In total, the majority of all sectoral aggregates experience lagged negative growth effects due to tropical cyclones. This finding clearly opposes the build-back-better hypothesis as well as the recovery to trend hypothesis. It rather points to the presence of (delayed) negative effects of tropical cyclones from which the sectors cannot recover. The result offers a better understanding of the finding of Hsiang \& Jina (2014), who show that tropical cyclones have long-lasting negative impacts on GDP growth by demonstrating which sectors are responsible for the long-lasting GDP downturn that they identify. Additionally, this finding undermines the urgency to analyze past influences beyond one or two years when examining the economic impacts of natural disasters.

\subsection{Indirect Effects}

The analysis of the past influences of tropical cyclone damage demonstrates that the sectoral growth response following a tropical cyclone is a complex undertaking. It remains unclear if there exists some key sector, which, if damaged, results in a negative shock for the other sectors. Additionally, it is unexplained how the sectors are interconnected and if their structural dependence changes. Therefore, in this section, I investigate, by means of the Input-Output analysis, how the sectors change their interaction after a tropical cyclone

\footnotetext{
22 The cumulative effects are calculated by F-tests of the respective lag lengths; for example, the coefficient and confidence intervals after two years are calculated by the F-test: Damage+L1.Damage+L2.Damage. The tests are conducted with the STATA command parmest (Newson 1998).

23 After one year, we can also detect a positive effect in the construction sector, which is not surprising given the higher number of orders due to reconstruction efforts.
} 

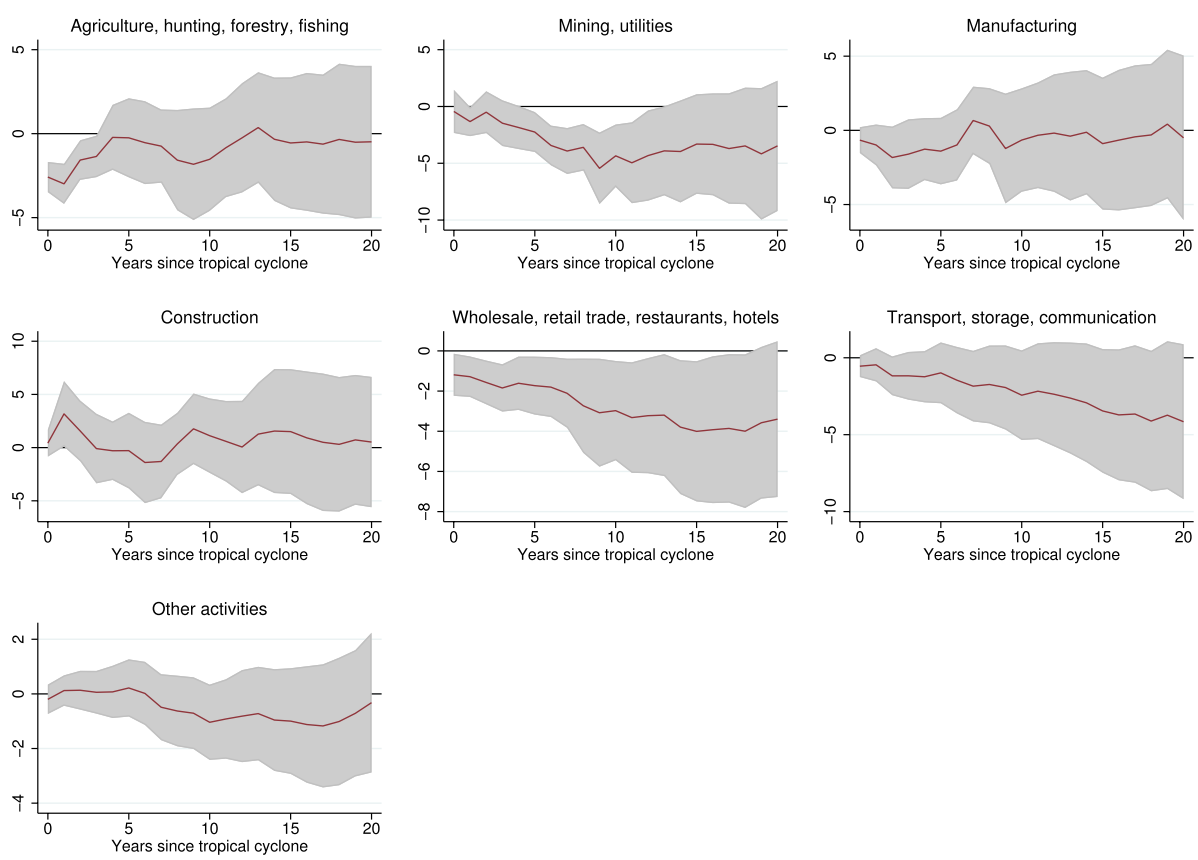

Fig. 6 Cumulative lagged influence of tropical cyclone damage on sectoral GDP growth (20 years). Notes The $y$-axis displays the cumulative coefficient of tropical cyclone damage on the respective per capita growth rates, and the $x$-axis shows the years since the tropical cyclone passed. The gray areas represent the respective $95 \%$ confidence intervals and the red line indicates the respective (connected) cumulative point estimates. The underlying estimations can be found in Tables 12-13 in Appendix A.5

has hit a country. This will provide further insights into whether production processes are seriously distorted by tropical cyclones. To the best of my knowledge, this is the first paper that analyzes global sectoral interactions after the occurrence of a tropical cyclone.

Since the sample period is reduced to 1990-2015 due to data availability, I re-estimated the regression model of the main specification 2 for the reduced sample of model 6 . Table 21 in Appendix A.5 reveals that even with the smaller sample, all previously found effects can be identified again. Therefore, we can be sure that the reduced sample size does not drive the new results.

Figure 7 illustrates the connections of significant changes of the Input-Output coefficient together with the effect size relative to the sample average of the respective Input-Output coefficients in parentheses (in \%) resulting from model 6. The coefficients are interpreted by a one standard deviation increase in tropical cyclone damage (above zero). ${ }^{24}$ For example, due to a standard deviation increase of tropical cyclone damage, the manufacturing sectors use $-0.66 \%$ less input from the construction sector aggregate relative to the average Input-Output coefficient (0.0045) to produce one unit of output. The red and green arrow colors represent significant negative and positive effects, whereas the color intensities denote different p-values. Circle diameters represent the average proportional

${ }^{24}$ The underlying estimations can be found in Tables 14-20 in Appendix A.5. 


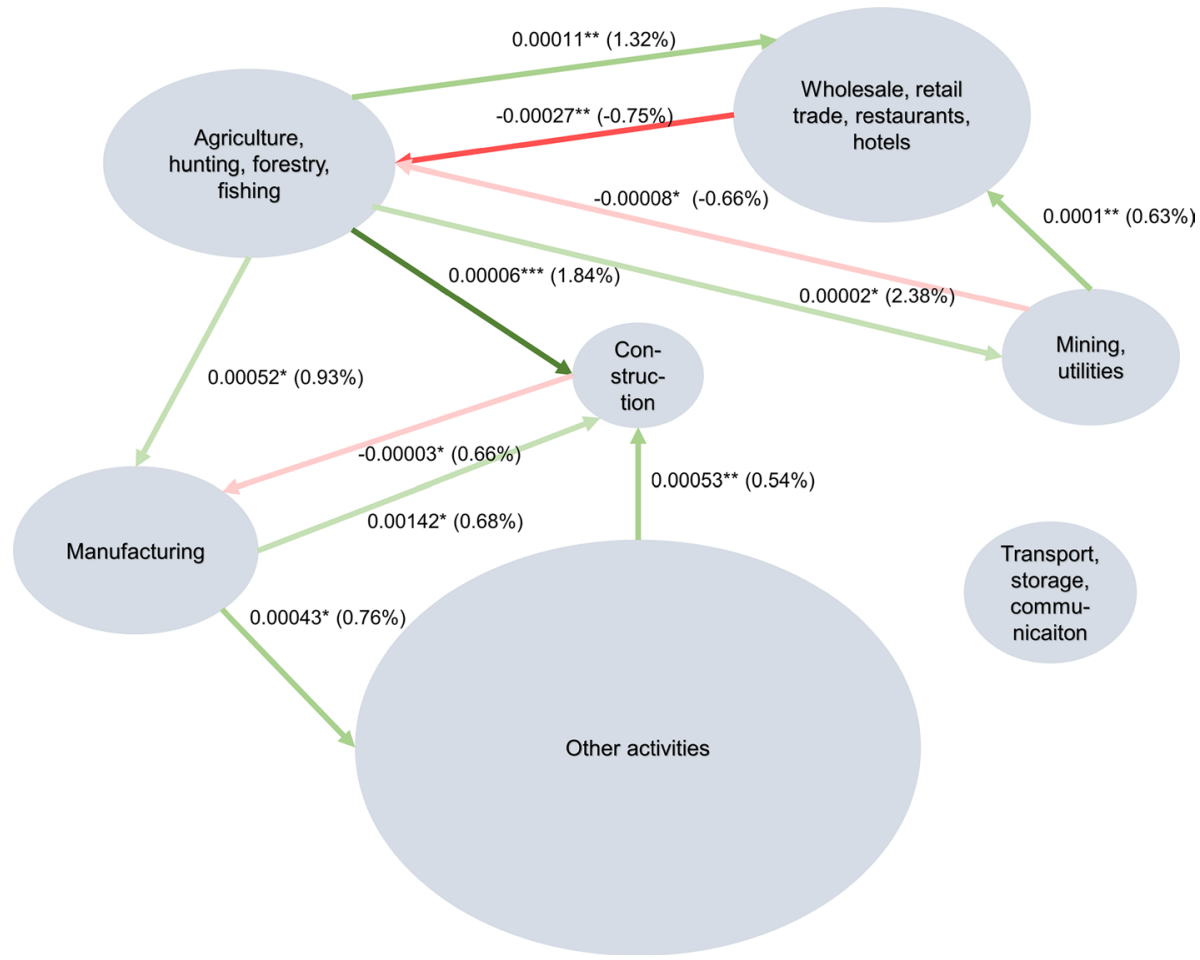

Fig. 7 Significant effects of tropical cyclone damage on Input-Output coefficients. Notes This figure shows the significant effects of a one standard deviation increase in tropical cyclone damage on the respective Input-Output coefficient. The number in parentheses compares the coefficients to the sample average of the respective Input-Output coefficient (in \%). Note that Input-Output coefficients can only range between 0 and 1. Circle diameter is proportional to the average sectoral share on total GDP. The arrows depict all significant coefficients between the sectoral aggregates, with negative coefficients in red and positive in green. The start of the arrow shows the input, and the end denotes the respective output. Asterisks and color intensities indicate $p$ values according to: $* * * p<0.01, * * p<0.05, * p<0.1$. (Color figure online)

share on total GDP ranging from $32 \%$ (other activities), over 12\% (manufacturing) to 6\% (construction). ${ }^{25}$

Tropical cyclones only lead to a small number of production process changes with coefficients being relatively small. Out of 49 parameter estimates, only 12 are significantly different from zero. ${ }^{26}$ As expected, the heavily damaged agriculture, hunting, forestry, and fishing sector aggregate experiences the most changes. It asks for less input from the wholesale, retail trade, restaurants, hotels and mining and utilities sector aggregates, which results from a supply shock in the agricultural sector. Concurrently, the construction sector demands significantly more input (1.84\%) from the agriculture, hunting, forestry, and fishing sector. This change can be regarded as reconstruction efforts, which is also reflected in the relatively rapid recovery of the agricultural sector aggregate in Fig. 6. The second

\footnotetext{
25 The other proportional shares on total GDP are: Wholesale, retail trade, restaurants, hotels (15\%); agriculture, hunting, forestry, fishing (14\%); mining and utilities (10\%); transport, storage, communication $(8 \%)$.
}

26 The manufacturing sectors use significantly less input from itself, which is not shown in Fig. 7. 


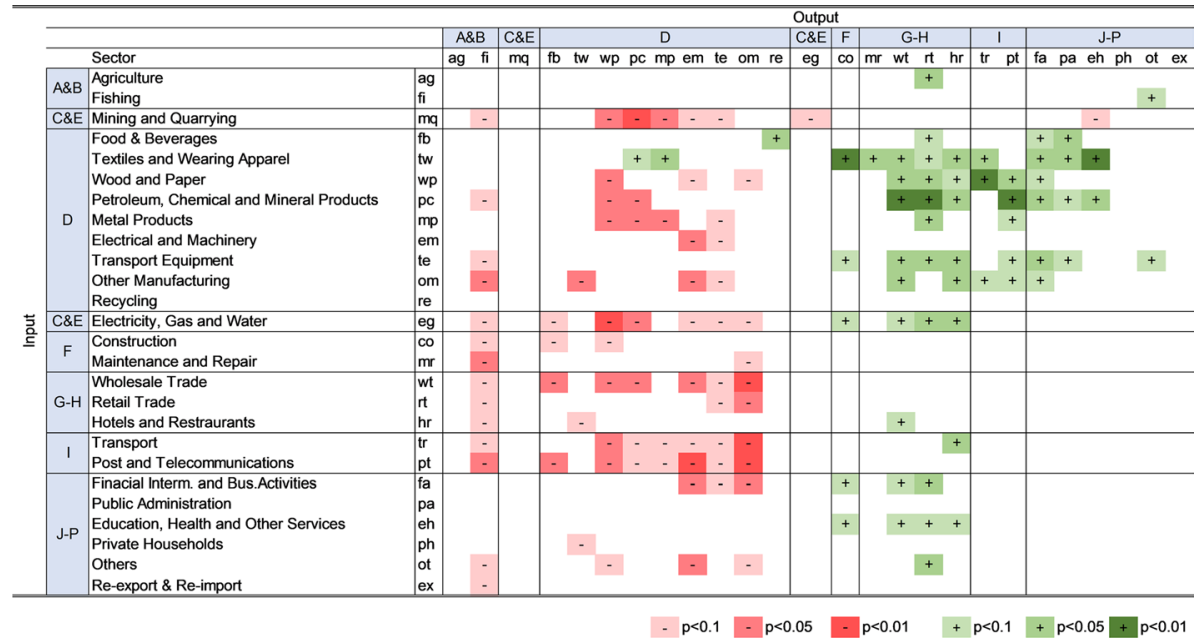

Fig. 8 Significant effects of tropical cyclone damage on disaggregated Input-Output coefficients. Notes The colored areas depict all significant coefficients between the sectors, with negative coefficients in red and positive in green. Color intensities indicate $p$ values according to: $p<0.01, p<0.05, p<0.1$. (Color figure online)

most indirectly affected sector is the construction sector. It demands more input from three other sector aggregates, while the manufacturing sectors use less input from it. Given these positive demand effects, one may ask why a significant contemporaneous positive direct effect for the construction sector cannot be seen. One reason could be that the destruction of productive capital outweighs the higher number of orders. However, one year later, as shown in Fig. 6, these positive demand shocks lead to a positive growth impulse in the construction sector.

Compared to the existing literature, the non-existing of a direct positive contemporaneous response of the construction sector is a new finding. For example, Hsiang (2010) finds an immediate positive response of the construction sector. In a similar manner, Mohan and Strobl (2017) find evidence that a positive growth effect of the construction sector, financed by international aid or government programs, lead to a fast recovery of SouthPacific Islands after tropical cyclones. ${ }^{27}$

Since the EORA26 database also offers the data decomposed for 26 sectors, this section demonstrates the results of model 6 in more detail. It would be tedious to show $26 \times 26$ regression models, Fig. 8 thus reduces the complexity of the analysis by showing only the sign of the significant coefficients together with color intensities representing different p-values.

Figure 8 reveals some patterns that are not visible on the aggregate level. The most interesting changes can be observed within the single sectors of the manufacturing $(D)$ aggregate. They ask significantly less input from other sector aggregates, while, at the same time, sectors from other aggregates ask more input from the manufacturing sectors.

\footnotetext{
${ }^{27}$ I also tested for lagged cumulative effects. The results can be found in Fig. 16 in Appendix A.5. They show that there are nearly no lagged responses present. I also checked for different lag lengths, but could hardly find any effect above a lag length of five years.
} 
These opposing production changes may be one of the reasons why we can see no aggregate direct cost effects. Nevertheless, it unveils the importance of the manufacturing sectors, as already demonstrated by their strong intersectoral connection in Fig. 4. This importance for the sectoral composition was already demonstrated by Bulte et al. (2018). The authors find that after the 2008 Wenchuan Earthquake neighboring counties suffer from indirect negative growth effects due to changes within the manufacturing sectors.

The sectors least affected by indirect changes are the agriculture (ag), recycling (re), private households (ph), and export (ex) sectors. Figure 8 also offers an explanation for the downturn of the mining and utilities $(C \& E)$ sector aggregate after some years, as shown in Fig. 6: The manufacturing sectors ask significantly less input from it. Additionally, it seems that the fishing sector is responsible for the negative supply shock in the agriculture, hunting, forestry, and fishing sector aggregate. Possible reasons for these indirect effects, could be changes in fishing patterns in response to tropical cyclones (Bacheler et al. 2019) or the destruction of vessels. While the importance of the fishing sector for indirect tropical cyclones' effects is a novel finding, it does not mean that other agricultural sectors do not exhibit negative direct effects. ${ }^{28}$

It is evident from this analysis that many potential production changes are canceled out because of counteracting indirect effects. This may be the reason why, on the aggregate level for indirect influences (see Fig. 7), we can only see significant changes in one quarter of all Input-Output connections, while in model 4 for the direct costs, only two sector aggregates are negatively affected. Furthermore, although the manufacturing sector shows no direct monetary damage, it is responsible for several changes in the production schemes of other sectors, leading to a monetary downturn in the mining and utilities $(C \& E)$ sectoral aggregate.

\subsection{Sensitivity Analysis}

To underline the credibility of my regression analyses, I test the sensitivity of my results in various ways. First, I run two randomization tests: a Placebo test by using leads instead of the contemporaneous measure of the damage variable and a Fisher randomization test, where I randomly permute the years. ${ }^{29}$ Second, to rule out potential omitted variable biases, I include additional climatological variables (precipitation and temperature) and a set of socioeconomic variables (population growth rate, economic openness, the growth rate of the gross capital formation, and logged per capita value added of the respective sector). ${ }^{30}$ Third, I test different trend specifications: region-specific, nonlinear, and no trends at all. Fourth, to alleviate concerns of biased uncertainty measures (Hsiang 2016), I calculate different standard errors: Newey-West standard errors with a lag length of 10

\footnotetext{
${ }^{28}$ In light of this finding, one could question the reliability of the agricultural weighting scheme for the damage variable. Therefore, I re-estimate the results of Eqs. 4 and 6 with the population weighted damage for the agricultural sectoral aggregate. Appendix Table 43 and 54 show that the results remain qualitatively unchanged.

${ }^{29}$ For the Placebo test I have to forward the damage variable by two periods, since the damage in $t$ index consists of the affected agricultural land/exposed population in $t-1$. To implement the Fisher randomization test, I use the code generated by $\mathrm{He} 3$ (2017) and randomly permute the years of the tropical cyclone damage variable for 2000 repetitions. By doing so, I test the null-hypothesis of no effect of the damage variable.

30 Since climatological impacts are most likely nonlinear, I also include squared precipitation and temperature in a further robustness test.
} 
years and Conley-HAC standard errors, allowing for a spatial and temporal dependence within a radius of $1000 \mathrm{~km}$ and within a time span of 10 years. Furthermore, I cluster the standard errors at broader regional levels to account for the event that tropical cyclones can also affect neighboring countries within one region. ${ }^{31}$ Additionally, I control for the yearly tropical cyclone frequency per year, I test a different damage variable (mean instead of maximum cubed wind speed per year), and include tropical cyclone basin fixed-effects in further robustness tests. Finally, I test two sub-samples, one with all potential outliers and one where I include only the countries exposed to tropical cyclones. ${ }^{32}$

Appendix A.6 exhibits the resulting robustness tests for the direct and indirect sectoral effects. ${ }^{33}$ For the direct sectoral effects, the significant results remain robust in all different specifications underlining their credibility for the empirical model used. ${ }^{34}$ While the placebo test yields no significant coefficients, the coefficients and p-value remain relatively stable in all remaining robustness tests, as summarized in Fig. 18. Furthermore, the results of the randomization test show that the $H_{0}$ of no effect of tropical cyclone damage can be rejected at the $1 \%$ and $5 \%$ level of confidence for the agriculture, hunting, forestry, and fishing and wholesale, retail trade, restaurants, and hotels sectors, respectively. The results of the Input-Output analysis, summarized in Appendix A.6.2, are a little less robust. However, on average, the previously found effects can be replicated for 12 out of the 15 robustness tests. ${ }^{35}$ Given the reduced quality of the data and a shorter time span (20 years), the Input-Output analysis still offers solid results.

\section{Conclusion}

This study provides an explanation about which sectors contribute to an overall negative GDP-effect of tropical cyclones identified by previous studies (Noy 2009; Strobl 2012; Elliott et al. 2015). To quantify the destructiveness of tropical cyclones, I construct a new damage measure based on meteorological data weighted by different exposure of the sectors. I show that tropical cyclones have a significantly negative impact on the annual growth rate of two sectoral aggregates: agriculture, hunting, forestry, and fishing and wholesale, retail trade, restaurants, and hotels. The dynamic analysis reveals that past tropical cyclones have a negative influence on the majority of sectors providing evidence for the no recovery hypothesis discussed in the literature. The Input-Output analysis demonstrates that production processes are only slightly disturbed by tropical cyclones. However, we still can learn from this analysis of how certain direct effects evolve.

The outcomes of this study can serve as a guide for local governments and international organizations to revise and refine their adaptation and mitigation strategies.

\footnotetext{
31 These regions include East Asia and Pacific, Europe and Central Asia, Latin America and Caribbean, Middle East and North Africa, North America, South Asia, and Sub-Saharan Africa.

32 Exposed countries are defined as having at least one positive damage observation over the sample period.

33 Appendix A.6 first shows the results of the randomization tests, followed by coefficient plots that summarize the remaining specifications. The underlying tables are only included for the direct sectoral effects, while the robustness tables for the Input-Output analysis are available upon request.

34 An exception forms the mean damage robustness test for the wholesale, retail trade, restaurants, and hotels sectors, where the coefficient turns slightly insignificant $(p=0.12)$.

35 The robustness tests that frequently fail are those with Conley-HAC and Newey-West standard errors.
} 
The findings can help them to identify the sectors for which they must reduce disaster risk. The results indicate that the policies should focus on the direct costs of tropical cyclones. Immediately after the disaster, the policy should concentrate on the agriculture, hunting, forestry, and fishing, and the wholesale, retail trade, restaurants, and hotels sector aggregates, as they are most vulnerable, and/or recovery measures have not been conducted efficiently in these sectors. Likewise, the contemporaneous, nonsignificant effect for the remaining sectors can be explained as a result of lower vulnerability and/or efficient recovery measures, which attenuate the potentially negative effect of tropical cyclones. In the years following the tropical cyclone, the efforts should be broadened to support the mining, and utilities, and the transport, storage, and communication sectors. Most worryingly, the majority of all sectors experience delayed negative effects underpinning how far away the international community remains from a buildback better or recovery to trend situation for tropical cyclone-affected economies. As the manufacturing sectors are responsible for much of the counterbalancing of indirect effects, they should not be forgotten by the policymakers, even though they show no direct negative effects.

Better post-disaster assistance is not the only required improvement; policymakers should also find ways to better prepare the affected sectors of their economy for possible effects of tropical cyclones before they strike. However, the presented results are generalized for 205 countries at most, and every specific country should make an analysis of their specific vulnerability and individual exposure. Nonetheless, the results can provide general guidance for international disaster relief organizations that are active in various countries on how to direct their long-run disaster relief programs. The results are particularly pressing, as tropical cyclones will continue to intensify due to global warming (Knutson et al. 2020), and, simultaneously, more people will be exposed to tropical cyclones. In this respect, the results of this research can also be used to calculate the future costs of climate change.

Supplementary Information The online version supplementary material available at https://doi.org/10.1007/ s10640-021-00541-5.

Acknowledgements I am grateful for comments made by Axel Dreher, Vera Eichenauer, Andreas Fuchs, Lennart Kaplan, Eric Strobl, and Christina Vonnahme. I further thank seminar participants at Heidelberg University (2016), the AERE Summer Conference in Breckenridge (6/2016), the EAERE Meeting in Zurich (06/2016), the BBQ Workshop in Salzburg (07/2016), the "Geospatial Analysis of Disasters: Measuring Welfare Impacts of Emergency Relief" Workshop in Heidelberg (07/2016), the Oeschger Climate Summer School in Grindelwald (08/2016), the Conference on Econometric Models of Climate Change in Oxford (9/2017), the Impacts World Conference in Potsdam (10/2017), and the 8th Annual Interdisciplinary Ph.D. Workshop in Sustainable Development at Columbia University (04/2018). Excellent proofreading was provided by Jamie Parsons and Harrison Bardwell.

Funding Open Access funding enabled and organized by Projekt DEAL.

Open Access This article is licensed under a Creative Commons Attribution 4.0 International License, which permits use, sharing, adaptation, distribution and reproduction in any medium or format, as long as you give appropriate credit to the original author(s) and the source, provide a link to the Creative Commons licence, and indicate if changes were made. The images or other third party material in this article are included in the article's Creative Commons licence, unless indicated otherwise in a credit line to the material. If material is not included in the article's Creative Commons licence and your intended use is not permitted by statutory regulation or exceeds the permitted use, you will need to obtain permission directly from the copyright holder. To view a copy of this licence, visit http://creativecommons.org/licenses/by/4.0/. 


\section{References}

Acemoglu D, Carvalho VM, Ozdaglar A, Tahbaz-Salehi A (2012) The network origins of aggregate fluctuations. Econometrica 80(5):1977-2016

Albala-Bertrand J-M (1993) Natural disaster situations and growth: a macro-economic model for sudden disaster impacts. World Dev 21(9):1417-1434

Angrist JD, Pischke J-S (2009) Mostly harmless econometrics: an empiricist's companion. Princeton University Press, Princeton

Auffhammer M, Hsiang SM, Schlenker W, Sobel A (2013) Using weather data and climate model output in economic analyses of climate change. Rev Environ Econ Policy 7(2):181-198

Aznar-Siguan G, Bresch DN (2019) CLIMADA v1: a global weather and climate risk assessment platform. Geosci Model Dev 12(7):3085-3097

Bacheler NN, Shertzer KW, Cheshire RT, MacMahan JH (2019) Tropical storms influence the movement behavior of a demersal oceanic fish species. Sci Rep 9(1):2045-2322

Bakkensen LA, Park D-SR, Sarkar RSR (2018) Climate costs of tropical cyclone losses also depend on rain. Environ Res Lett 13(7):074034.

Barrot J-N, Sauvagnat J (2016) Input specificity and the propagation of idiosyncratic shocks in production networks. Q J Econ 131(3):1543-1592

Berlemann M, Wenzel D (2018) Hurricanes, economic growth and transmission channels: empirical evidence for countries on differing levels of development. World Dev 105:231-247

Bertinelli L, Strobl E (2013) Quantifying the local economic growth impact of hurricane strikes: an analysis from outer space for the Caribbean. J Appl Meteorol Climatol 52(8):1688-1697

Blanc E, Strobl E (2016) Assessing the impact of typhoons on rice production in the Philippines. J Appl Meteorol Climatol 55(4):993-1007

Boehm CE, Flaaen A, Pandalai-Nayar N (2019) Input linkages and the transmission of shocks: firm-level evidence from the 2011 Tohoku earthquake. Rev Econo Stat 101

Botzen WJW, Deschenes O, Sanders M (2019) The economic impacts of natural disasters: a review of models and empirical studies. Rev Environ Econ Policy 13(2):167-188

Bulte E, Xu L, Zhang X (2018) Post-disaster aid and development of the manufacturing sector: lessons from a natural experiment in China. Eur Econ Rev 101:441-458

Chhibber A, Laajaj R (2008) Disasters, climate change and economic development in Sub-Saharan Africa: lessons and directions. J Afr Econ 17(Supplement2):ii7-ii49

Cole MA, Elliott RJR, Okubo T, Strobl E (2019) Natural disasters and spatial heterogeneity in damages: the birth, life and death of manufacturing plants. J Econ Geogr 19(2):373-408

Cuaresma JC, Hlouskova J, Obersteiner M (2008) Natural disasters as creative destruction? Evidence from developing countries. Econ Inquiry 46(2):214-226

de Mel S, McKenzie D, Woodruff C (2012) Enterprise recovery following natural disasters. Econ J 122(559):64-91

Dell M, Jones BF, Olken BA (2014) What do we learn from the weather? The new climate-economy literature. J Econ Lit 52(3):740-798

Dupor B (1999) Aggregation and irrelevance in multi-sector models. J Monet Econ 43(2):391-409

Elliott RJ, Strobl E, Sun P (2015) The local impact of typhoons on economic activity in China: a view from outer space. J Urban Econ 88:50-66

Elliott RJ, Liu Y, Strobl E, Tong M (2019) Estimating the direct and indirect impact of typhoons on plant performance: evidence from Chinese manufacturers. J Environ Econ Manag 98:102252

Elsner JB, Kossin JP, Jagger TH (2008) The increasing intensity of the strongest tropical cyclones. Nature 455(7209):92-95

Emanuel K (2011) Global warming effects on U.S. hurricane damage. Weather Clim Soc 3(4):261-268

Felbermayr G, Gröschl J (2014) Naturally negative: the growth effects of natural disasters. J Dev Econ 111:92-106

Fetzer T (2020) Can workfare programs moderate conflict? Evidence from India. J Eur Econ Assoc 18(6):3337-3375

Forster J, Schuhmann PW, Lake IR, Gill JA (2012) The influence of hurricane risk on tourist destination choice in the Caribbean. Clim Change 114(3):745-768

Ghosh A (1958) Input-output approach in an allocation system. Economica 25(97):58-64

Gröger A, Zylberberg Y (2016) Internal labor migration as a shock coping strategy: evidence from a typhoon. Am Econ J Appl Econ 8(2):123-153

Guha-Sapir D, CRED (2020) EM-DAT: the emergency events database. Technical report, Université catholique de Louvain (UCL). www.emdat.be 
Haimes YY, Jiang P (2001) Leontief-based model of risk in complex interconnected infrastructures. J Infrastruct Syst 7(1):1-12

Hallegatte S, Przyluski V (2010) The economics of natural disasters: concepts and methods. World Bank Policy Research Working Paper 5507. http://hdl.handle.net/10986/3991

Heinen A, Khadan J, Strobl E (2018) The price impact of extreme weather in developing countries. Econ J 129(619):1327-1342

Heß S (2017) Randomization inference with Stata: a guide and software. Stata J 17(3):630-651

Holland GJ (1980) An analytic model of the wind and pressure profiles in hurricanes. Mon Weather Rev 108(8):1212-1218

Horvath M (2000) Sectoral shocks and aggregate fluctuations. J Mon Econ 45(1):69-106

Hsiang SM (2010) Temperatures and cyclones strongly associated with economic production in the Caribbean and Central America. Proc Natl Acad Sci USA 107(35):15367-15372

Hsiang SM (2016) Climate econometrics. Ann Rev Resour Econ 8(1):43-75

Hsiang SM, Jina AS (2014) The causal effect of environmental catastrophe on long-run economic growth: evidence from 6,700 cyclones. NBER Working Paper 20352. http://www.nber.org/papers/ w20352.pdf

Islam N (1995) Growth empirics: a panel data approach. Q J Econ 110(4):1127-1170

Klein Goldewijk K, Beusen A, Doelman J, Stehfest E (2017) Anthropogenic land use estimates for the holocene-HYDE 3.2. Earth Syst Sci Data 9(2):927-953

Klomp JG, Valckx K (2014) Natural disasters and economic growth: a meta-analysis. Glob Environ Change 26:183-195

Knapp KR, Kruk MC, Levinson DH, Diamond HJ, Neumann CJ (2010) The international best track archive for climate stewardship (IBTrACS). Bull Am Meteorol Soc 91(3):363-376

Knutson T, Camargo SJ, Chan JC, Emanuel K, Ho C-H, Kossin J, Mohapatra M, Satoh M, Sugi M, Walsh K et al (2020) Tropical cyclones and climate change assessment: part II: projected response to anthropogenic warming. Bull Am Meteorol Soc 101(3):E303-E322

Korty R (2013) Hurricane (typhoon, cyclone). In: Bobrowsky PT (ed) Encyclopedia of natural hazards. Springer, Dordrecht, New York, pp 481-494

Kousky C (2014) Informing climate adaptation: a review of the economic costs of natural disasters. Energy Econ 46:576-592

Kruk MC, Knapp KR, Levinson DH (2010) A technique for combining global tropical cyclone best track data. J Atmos Ocean Technol 27(4):680-692

Lazzaroni S, van Bergeijk P (2014) Natural disasters' impact, factors of resilience and development: a meta-analysis of the macroeconomic literature. Ecol Econ 107:333-346

Le Cozannet G, Modaressi H, Pedreros R, Garcin M, Krien Y, Desramaut N (2013) Storm surges. In: Bobrowsky PT (ed) Encyclopedia of natural hazards. Springer, Dordrecht and New York, p 940

Lenzen M, Kanemoto K, Moran D, Geschke A (2012) Mapping the structure of the world economy. Environ Sci Technol 46(15):8374-8381

Lenzen M, Moran D, Kanemoto K, Geschke A (2013) Building Eora: a global multi-region input-output database at high country and sector resolution. Econ Syst Res 25(1):20-49

Lenzen M, Malik A, Kenway S, Daniels P, Lam KL, Geschke A (2019) Economic damage and spillovers from a tropical cyclone. Nat Hazards Earth Syst Sci 19(1):137-151

Loayza NV, Olaberría E, Rigolini J, Christiaensen L (2012) Natural disasters and growth: going beyond the averages. World Dev 40(7):1317-1336

Mendelsohn R, Emanuel K, Chonabayashi S, Bakkensen L (2012) The impact of climate change on global tropical cyclone damage. Nat Clim Change 2(3):205-209

Miranda JJ, Ishizawa OA, Zhang H (2020) Understanding the impact dynamics of windstorms on short-term economic activity from night lights in Central America. Econ Disasters Clim Change 4(3):657-698

Mohan P (2017) Impact of hurricanes on agriculture: Evidence from the Caribbean. Nat Hazards Rev 18(3):04016012

Mohan P, Strobl E (2017) The short-term economic impact of Tropical Cyclone Pam: an analysis using VIIRS nightlight satellite imagery. Int J Remote Sens 38(21):5992-6006

Mohan PS, Spencer N, Strobl E (2019) Natural hazard-induced disasters and production efficiency: moving closer to or further from the frontier? Int J Disaster Risk Sci 10(2):166-178

Munich R (2018) NatCatSERVICE_Relevant natural loss events worldwide 1980-2018. https://www. munichre.com/en/solutions/for-industry-clients/natcatservice.html

Newey WK, West KD (1987) A simple, positive semi-definite, heteroskedasticity and autocorrelation consistent covariance matrix. Econometrica 55(3):703-708

Newson R (1998) PARMEST: Stata module to create new data set with one observation per parameter of most recent model. Stat Softw Compon S352601. https://ideas.repec.org/c/boc/bocode/s352601.html 
Nguyen CN, Noy I (2019) Measuring the impact of insurance on urban earthquake recovery using nightlights. J Econ Geogra 20(3):857-877

NHC (2016) National hurricane center forecast verification. http://www.nhc.noaa.gov/verification/verif y5.shtml

Nickell SJ (1981) Biases in dynamic models with fixed effects. Econometrica 49(6):1417-1426

Noy I (2009) The macroeconomic consequences of disasters. J Dev Econ 88(2):221-231

Onuma H, Shin KJ, Managi S (2020) Short-, medium-, and long-term growth impacts of catastrophic and non-catastrophic natural disasters. Economics of Disasters and Climate Change (pp. 2511-1299)

Oosterhaven J (2017) On the limited usability of the inoperability IO model. Econ Syst Res 29(3):452-461

Ouattara B, Strobl E (2013) The fiscal implications of hurricane strikes in the Caribbean. Ecol Econ $85: 105-115$

Schreck CJ, Knapp KR, Kossin JP (2014) The impact of best track discrepancies on global tropical cyclone climatologies using IBTrACS. Mon Weather Rev 142(10):3881-3899

Sieg T, Schinko T, Vogel K, Mechler R, Merz B, Kreibich H (2019) Integrated assessment of short-term direct and indirect economic flood impacts including uncertainty quantification. PLoS ONE 14(4):1-21

Strobl E (2011) The economic growth impact of hurricanes: Evidence from U.S. coastal counties. Rev Econ Stat 93(2):575-589

Strobl E (2012) The economic growth impact of natural disasters in developing countries: evidence from hurricane strikes in the Central American and Caribbean Regions. J Dev Econ 97(1):130-141

Terry JP (2007) Tropical cyclones: climatology and impacts in the South Pacific. Springer, New York, London

Toya H, Skidmore M (2007) Economic development and the impacts of natural disasters. Econ Lett 94(1):20-25

United Nations Statistical Division (2015a). Glossary-definition of term: value added-gross. https://unsta ts.un.org/unsd/snaama/Metadata/Glossary\#

United Nations Statistical Division (2015b) Methodology for the national accounts main aggregates database. https://unstats.un.org/unsd/snaama/assets/pdf/methodology.pdf

United Nations Statistical Division (2015c) UN data. http://data.un.org/Explorer.aspx?d=SNAAMA

University of East Anglia Climatic Research Unit, Harris IC, Jones PD (2017) CRU TS4.01: climatic research unit (CRU) time-series (TS) version 4.01 of high-resolution gridded data of month-by-month variation in climate (Jan. 1901-Dec. 2016). Technical report, Centre for Environmental Data Analysis (CEDA)

World Bank (2010) Natural hazards, unnatural disasters: the economics of effective prevention: overview. http://hdl.handle.net/10986/2512

Yang D (2008) Coping with disaster: the impact of hurricanes on international financial flows, 1970-2002. B.E. J Econ Anal Policy 8(1):13

Publisher's Note Springer Nature remains neutral with regard to jurisdictional claims in published maps and institutional affiliations. 